\title{
Analog processes for digitally native students
}

\section{George Hajian}

Auckland University of Technology

When it comes to teaching communication design, educators today are not only faced with diverse pedagogical concerns and considerations, but also the necessity to adapt their strategies during unusual times.

Being technologically inclined and digitally native, new intakes of communication design students lack aesthetic awareness and sensitivity when it comes to designing for print. Growing up with social media and constant digital connectivity, students struggle to understand the relationship between communication, legibility, and usability of an analog, printed publication.

Students are very comfortable in exploring design or manipulating graphic forms and text digitally, but when it comes to transcribing these onto non-scalable substrates, ie: paper, they struggle with legibility,

hierarchy, size, and weight of the letterforms. To assist with teaching and learning, studio activities were designed to increase students' functional, aesthetic, and formal awareness of printed text.

Using a subject pool of 18 students, this qualitative research looks into the impact of 2 studio activities, to help 2 nd-year communication design undergraduates slow down, and appreciate the optic qualities of letterforms and printed content. 